The botanical value of the "Flora", as was to be expected from the authorship, is considerably greater than that of many works of a similar kind. Full treatment is accorded to critical genera and, in most cases, their distribution in the county is worked out in detail (for example, Batrachian Ranunculus, Viola, Epilobium, Rubus, Rosa, etc.). A useful feature is the constant reference to the literature of difficult groups. It is to be regretted, however, that these references do not include work on experimental and genetical lines as well as purely systematic papers. Under Erophila, for example, the work of Rosen and Winge might have been mentioned as well as that of Jordan; and under Hieracium there is no reference to Ostenfeld's researches on the apogamy of the genus. In omitting work of this type an opportunity has been missed of bringing into closer touch the old and the new schools of taxonomy. Unless this can be done, no further advance in our knowledge of the British flora is possible.

This, however, is a general criticism, applicable, unfortunately, to a great deal of the work on the British flora during the last thirty years, and does not prevent the volume from being one of the most attractively produced and valuable of our county 'floras'. The illustrations of places of botanical interest in the county and the two maps add considerably to its interest, and also, unfortunately, to its price, which is surprisingly high, even for a work of such limited circulation. Dr. Pearsall is to be congratulated on bringing to successful completion a work which has passed through so many vicissitudes during the last forty years.

\section{Practical Organic Chemistry}

Laboratory Methods of Organic Chemistry. By L. Gattermann. Completely revised by Heinrich Wieland. Translated from the Twenty-second German Edition by Dr. W. MeCartney. Pp. xvii +416. (London: Macmillan and Co., Ltd., 1932.) 17s. net.

THIs is one of the classic textbooks of the organic chemist; there can be few who have not made use of it at the beginning of their manipulative training even in Great Britain, and the reviewer can plead guilty to struggling with the first edition, dated Heidelberg, August, 1894, in the original German in his student days. In issuing the nineteenth edition from Freiburg in 1925, H. Wieland, the successor to Gattermann, emphasised the fact that the equipment which sufficed during the last three decades has now become insufficient for those who desire to work at present-day problems, so that in rewriting the book the theoretical and practical requirements have been deliberately increased. We now have the twentysecond edition dated from Munich in July, 1930, with the English translator's date of April, 1932, which shows many changes, all directed to place the student in contact with modern fields of inquiry. Thus, two enzyme preparations have been included, and a biochemical flavour, showing the trend of the times, is also imparted by the preparation of natural compounds, such as furfural, glucose, arginine, nicotine, hæmin and the constituents of bile.

The number of preparations is, of course, in excess of what any student can complete in his course of about a year's training-in Munich it is usual for the student to carry out fifty to sixty preparations, as well as some six or eight from the original literature. The translation into English appears to be well made; and this new edition will be welcomed by students of practical organic chemistry unfamiliar with the German language. Serious students ought, however, to work through such a book in the original German-in no other way can they obtain so easily the essential knowledge of the construction and vocabulary of chemical German.

It would be attractive to use the first and the newest editions as the basis for moralising on the advances in organic chemistry during thirtysix years and on the method of teaching it, but lack of space prevents this being done here. At least it is more important to-day than ever that the worker must be a practical manipulator of the highest skill ; and Gattermann's course of work is admirably designed to attain that end.

E.F.A.

\section{On the Roof of the Forest}

A Naturalist in the Guiana Forest. By Major R. W. G. Hingston. Pp. xiii $+384+16$ plates. (London: Edward Arnold and Co., 1932.) 18s. net.

THE treetop canopy of the Amazons forest naturalists ; but hitherto the difficulties of exploration in this 'forest above the forest' have been thought to be almost insurmountable. The success of Major Hingston and his colleagues of 